\title{
Fluid Mechanics of Intrusives
}

\author{
Jónas Elíasson ${ }^{1,2}$ \\ ${ }^{1}$ School of Engineering and Natural Sciences, University of Iceland and Visiting, Reykjavik, Iceland \\ ${ }^{2}$ Kyoto University Disaster Prevention Research Institute S-535D, Gokasho, Uji, Kyoto, Japan \\ Email: jonase@hi.is
}

Received October 22, 2013; revised November 21, 2013; accepted December 14, 2013

Copyright (C) 2013 Jónas Elíasson. This is an open access article distributed under the Creative Commons Attribution License, which permits unrestricted use, distribution, and reproduction in any medium, provided the original work is properly cited. In accordance of the Creative Commons Attribution License all Copyrights (C) 2013 are reserved for SCIRP and the owner of the intellectual property Jónas Elíasson. All Copyright (C) 2013 are guarded by law and by SCIRP as a guardian.

\begin{abstract}
The fluid mechanics of dike emplacement are analyzed using the translatory wave theory. The stress strain relations in the host rock are assumed linear and the fracture resistance of the host rock is assumed small. The resulting model is a flowing dyke progressing upwards to the surface with constant speed and a very small side slope. Apart from the topmost section, the form of the dyke is very close to the static form corresponding to the magma pressure in a no-flow situation. Two scales are found that control the flow, a width scale and a composite stiffness parameter for the host rock, representing the properties of the rock and the magma such as elasticity and viscosity. The theory explains a number of special features for dykes that are already known by researchers. It also adds two new points, the most interesting being that the composite stiffness of the rock can be estimated from field observations of the downwards widening angle of the dyke.
\end{abstract}

Keywords: Intrusion; Magma Flow; Translatory Wave; Rock Stress

\section{Introduction}

Emplacement of dykes is a very complex hydro and thermodynamic process. There exists a wide variety of research papers on this subject where a lot of data are published. The process when the local density difference controls the height of magma ascent is investigated in [1] They find that the magma can reach few kilometres above neutral buoyancy level. [2] published data for two kimberlite dyke swarms. They find average thick-nesses of the dykes to be 0.64 and 0.40 meters respectively, with variations of the same order of magnitude. In [3], Gudmundsson discusses the formation of dykes in Iceland and concludes that the minimum tensile strength makes them intrude the subvertical joints in lava flows but only $1 \%-2 \%$ reach the surface. In [4] are observations of dykes width in three intra-plate volcanoes and it is found to increase linearly as a function of distance from the volcanic centre. This is explained by decreasing intrusion frequency.

The dyke emplacement is a process controlled by the stresses and strains in the host rock and this is the subject of numerous papers. In [5] the magma flow in a crack is modelled, producing many interesting results such as the equilibrium width dyke where the flow resistance at the walls is exactly balanced by the buoyancy of the warm magma. The influence of the viscosity is clearly stated in [6]. According to [7], the fracture resistance of the elastic medium can be neglected, and this is followed here, and they furthermore show that the propagation of the fracture is limited by the viscosity of the magma. Professor Walker has written numerous papers on the geology of Iceland, especially the eastern county. Of his numerous papers, only [8] is listed here.

The following treatment is based on the translatory wave theory. It is a fluid flow theory, specially constructed for isolated flow disturbances. It is therefore very suitable for flows penetrating an unusual environment like floods running over dry land [9], density driven gravity waves [10] and tsunamis [11]; it has not been used before on the dyke emplacement problem.

\section{Lithostatic Considerations}

In a rock formation overlaying a magma chamber or a sill, the stress situation can be described as Figure 1(a). The vertical stress, considered here as the largest principal stress, is the weight of the overburden $\left(\rho_{h}\right.$ the density 


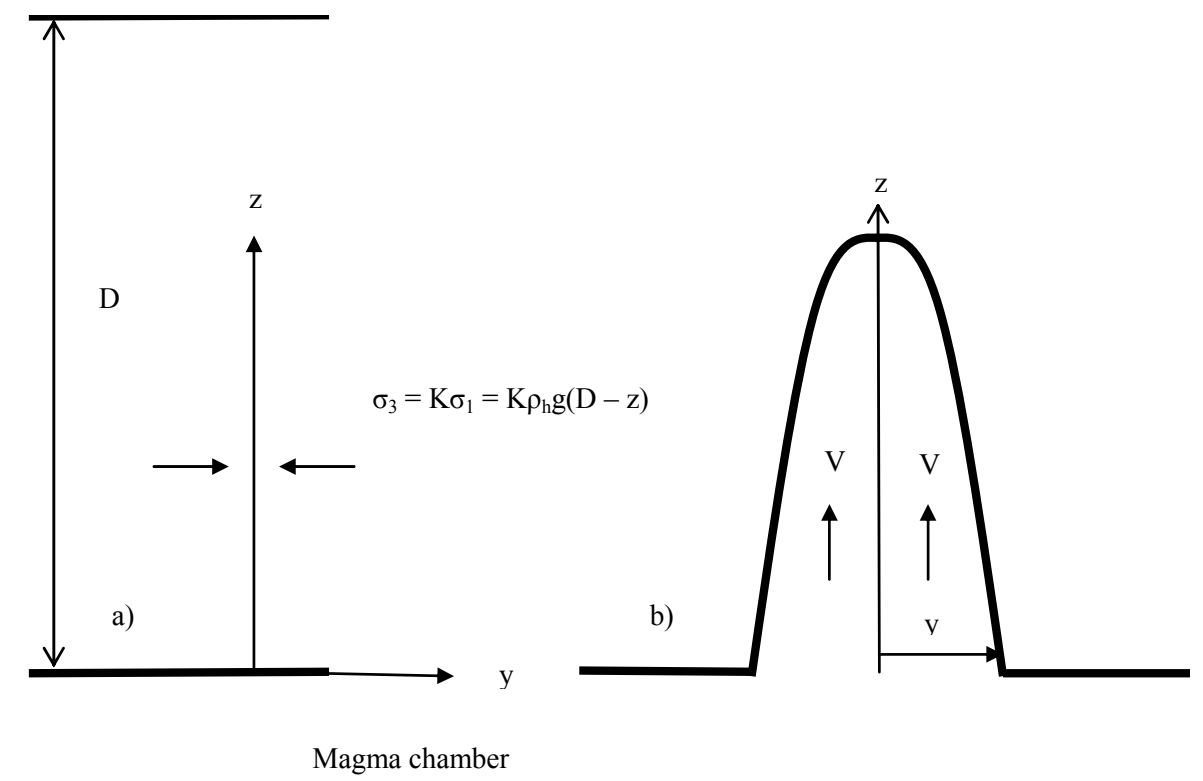

Figure 1. (a) Before onset of intrusion formation; (b) The intrusion process.

of the host rock) and the smaller lateral principal stress is proportional to it with an unknown proportionality factor $\mathrm{K}$. In a formation in a positive strain situation (elongation) we will have $\mathrm{K}_{\mathrm{a}}<\mathrm{K}<\mathrm{K}_{\mathrm{o}}$ where index "a" refers to active stress, but "o" to neutral stress (no strain) situation. In a negative strain situation (compression) we will have $\mathrm{K}_{\mathrm{o}}<\mathrm{K}<\mathrm{K}_{\mathrm{p}}$ where index " $\mathrm{p}$ " refers to passive stress.

The onset of a dyke intrusion may be due to several reasons, all beyond the scope of this paper. The dyke originates from the magma chamber (or the sill), it is supposed to supply fluid magma to the dyke without significant pressure changes at the source. When in progress, the intrusion will let hydrostatic magma pressure of the order of magnitude $\sigma_{1}=\rho_{\mathrm{h}} \mathrm{gD}$ into a fracture that progresses upwards.

As $\sigma_{1}>\sigma_{2}$ the stress difference will push the walls of the fracture outward to a distance y from the original position (Figure 1(b)). The displacement of the walls will evoke a reaction stress $\sigma_{\mathrm{r}}=$ Sy where $\mathrm{S}$ is a stiffness coefficient. As long as y is small and transient pressure changes or permanent (plastic) deformation of the host rock has not taken place, the deformation is elastic and $\mathrm{S}$ is independent of $\mathrm{y}$.

\section{Fluid Dynamics of an Intrusion}

Pressure and shear can be supposed to dominate acceleration forces in the migration of the intrusion upwards. Here the intrusion is supposed to migrate like a translatory wave with constant celerity up the fracture in the host rock.

In Figure 1 the static pressure $\mathrm{p}(\mathrm{z})$ (corresponding to $\mathrm{V}=0$ ) in the intrusion can be assumed somewhat higher than the horizontal stress, or $p(z)=\rho_{h} g D-\rho_{m} g z \geq K \rho_{h} g(D-z)+S y$. The difference is due to the pressure gradient in the flow. The magma is a very viscous substance so when $\mathrm{V}>0$ (Figure 1(b)) we will have:

$$
\mathrm{y} \leq \frac{\rho_{\mathrm{h}} \mathrm{g}}{\mathrm{S}}\left((1-\mathrm{K}) D-\mathrm{z}\left(\frac{\rho_{\mathrm{m}}}{\rho_{\mathrm{h}}}-K\right)\right)
$$

The equal sign is valid in the no flow $(\mathrm{V}=0)$ situation. $\rho_{\mathrm{m}} / \rho_{\mathrm{h}}-\mathrm{K}$ is most likely positive as the density ratio is only slightly different from one, so for constant $\mathrm{S}$, the intrusion width will decrease upwards. Variable $\mathrm{S}$ will be considered later.

The wave form progresses with more or less constant form and velocity V (Figure 1(b)), so the velocity of the fluid will also be V. Then the cross-section integrated continuity equation:

$$
\frac{\partial \mathrm{q}}{\partial \mathrm{z}}+\frac{\partial \mathrm{y}}{\partial \mathrm{t}}=0 \Rightarrow \frac{\partial \mathrm{q}}{\partial \mathrm{z}}-\mathrm{V} \frac{\partial \mathrm{y}}{\partial \mathrm{z}}=0 \Rightarrow \mathrm{q}=\mathrm{Vy}
$$

allows the solution:

$$
\mathrm{q}=\mathrm{Vy} \quad \mathrm{y}=\mathrm{y}(\xi) \quad \xi=\mathrm{z}-\mathrm{Vt}
$$

The continuity equation for the flow will then be automatically fulfilled when $\mathrm{V}$ is constant. Momentum loss is caused by the friction against the walls.

When the lateral pressure in the host rock and in the flowing magma is assumed equal the momentum equation becomes.

$$
\frac{d y}{d \xi}=-\left(\frac{3 v_{m} V}{g y^{2}}+\left(1-K \frac{\rho_{h}}{\rho_{m}}\right)\right) \frac{g \rho_{m}}{S}
$$

This equation integrates to the static value of y (equal 
sign in Equation (1)) in the case $\mathrm{V}=0$. For $\mathrm{V}$ positive, the equation can also be integrated. Defining following constants

$$
y_{0}^{2}=\frac{3 v_{m} V}{g\left(1-K \rho_{h} / \rho_{m}\right)} ; C_{h}=\frac{S}{g \rho_{h}\left(\rho_{m} / \rho_{h}-K\right)}
$$

We call $\mathrm{y}_{0}$ the width scale and $\mathrm{C}_{\mathrm{h}}$ the composite stiffness of the host rock.

Integrating Equation (3) we obtain

$$
\xi / \mathrm{y}_{0}=-\mathrm{C}_{\mathrm{h}}\left(\mathrm{y} / \mathrm{y}_{0}-\arctan \left(\mathrm{y} / \mathrm{y}_{0}\right)\right)
$$

The function Equation (5) has very different properties for $\mathrm{y} / \mathrm{y}_{0}$ large and small respectively. It should be noted that $\xi$ takes only negative values in $\mathrm{z}<\mathrm{D}$ as $\mathrm{z}=\mathrm{Vt}$ is the top of the intrusion. In applying limits to Equation (5) it must be noted that $\mathrm{p}(\mathrm{z})$ cannot exceed the static value and this sets a limit on $y, y_{\max }$ that has to be deducted from Equation (1) (equal sign). When this happens the flow can become buoyant and Equation (5) will no longer be valid. If the flow continues, $\mathrm{y}_{\max }$ progresses upwards with $\mathrm{V}$ and for the flow below the value of $\mathrm{z}$ where the constant width starts, the equations in [5] for buoyant magma flows will be valid.

We have considered $\mathrm{S}$ to be a constant, that is necessary to do, but only piecewise. If $\mathrm{S}$ changes when the dyke breaks from one rock layer into another with different $\mathrm{S}$, the width scale and the composite stiffness will change, but after a small intermediate z-distance the process will adapt to the new values. E.g. when $S$ diminishes the width scale and the composite stiffness will go down and the dyke widens upwards. If it stops a little later, we may have the well-known teardrop shaped intrusions [12].

\section{Limiting Values and Estimations of Parameters}

\subsection{Dyke Dimensions}

At the level $\mathrm{z}=0$ the pressure is the lithostatic pressure in all directions as the magma is liquid. This sets the maximum value y can take as the biggest possible halfwidth of the intrusion, it will be in $\mathrm{z}=0$. Naming it $\mathrm{W} / 2$ we will have:

$$
\mathrm{y}_{\max }=\mathrm{W} / 2=\frac{\rho_{\mathrm{h}} \mathrm{g}}{\mathrm{S}}(1-\mathrm{K}) \mathrm{D}
$$

When Equation (5) reaches this value in $\mathrm{z}=0$ at time $\mathrm{t}$, the dyke is $\mathrm{L}=\mathrm{Vt}$ high up in the host rock. Inserting Equation (6) in Equation (5) and evaluating gives,

$$
\mathrm{L} / \mathrm{D}=\left(1-\frac{\Delta}{1-\mathrm{K}}\right)\left(1-\frac{\arctan \left(\mathrm{y}_{\max } / \mathrm{y}_{0}\right)}{\mathrm{y}_{\max } / \mathrm{y}_{0}}\right)
$$

The relative density difference $\left(\rho_{\mathrm{h}}-\rho_{\mathrm{m}}\right) / \rho_{\mathrm{h}}$ is called $\Delta$.
There is nothing in the fluid mechanics to stop the dyke from penetrating the surface, so Equation (7) may be evaluated for $\mathrm{L}=\mathrm{D}$. This gives.

$$
\frac{\Delta}{1-\mathrm{K}}=\frac{\arctan \left(\mathrm{y}_{\max } / \mathrm{y}_{0}\right)}{\mathrm{y}_{\max } / \mathrm{y}_{0}}
$$

As $\Delta /(1-\mathrm{K})$ is a small number, $\mathrm{y}_{\max }>\mathrm{y}_{0}$. When the right side of Equation (8) is known, finding $\mathrm{y}_{0}$ is not a problem. For $\mathrm{y}_{\max } / \mathrm{y}_{0}>3-5$, inserting $\arctan \left(\mathrm{y}_{\max } / \mathrm{y}_{0}\right)=$ $\pi / 2$ will give sufficiently accurate results for $\mathrm{y}_{\max } / \mathrm{y}_{0}$. Then $\mathrm{y}_{0}$ is found and from it the velocity $\mathrm{V}$ by using the definition of the dyke width scale.

\subsection{Composite Stiffness}

The liquid magma seeks out cracks and other weaknesses in the host rock, there are enough of them. In a crack or a fault there is no tensile strength, any pressure above the lithostatic will cause them to yield. Properties for igneous rocks do therefore not apply; this is clearly stated in [5].

The elastic deformation of the dyke's wall's follows Hook's law. The total deformation is y, the length of influence where this deformation is taken up by the rock is $\mathrm{L}$, say, then $\mathrm{S}=\mathrm{E} / \mathrm{L}$. The most likely measurements available to estimate seem to the storage coefficients inferred from short time pumping tests into 2 - $3 \mathrm{~km}$ deep confined aquifers as there is direct linear relationship between the storage coefficient and E. Sandstones and unconsolidated lava rocks usually have $\mathrm{E}$ of the order of magnitude $10 \mathrm{GPa}$. L is estimated equal to the depth to the magma, which in this case will be set to $3 \mathrm{~km}$ as the pumping tests wells reach this maximum depth. This yields

$$
\mathrm{S}=3.3 \mathrm{MPa} / \mathrm{m}
$$

The analogy between water and magma injection may seem farfetched, but in the short term this is the same displacement process. In the long term however there is a large difference. When pumping a water slug into an aquifer, we will have elastic deformation just around the injection point and a sudden rise in the pressure. When time goes the water in the slug will percolate away and the pressure differences evened out in transient pressure variations. The magma cannot do this. But the strain it creates may very well undergo transient changes because of fluid flow in the rock. This contributes to regenerating the pressure field by spreading the pressure disturbance of the dyke to a larger area after the dyke has frozen in place.

The $\mathrm{K}$ factor is somewhere between 0,3 and 1 . The estimate $\mathrm{K}=0.6$ is used. This gives us the dimensionless composite stiffness:

$$
\mathrm{C}_{\mathrm{h}}=128
$$




\subsection{Upwards Dyke Slope}

Equation (5) gives $=0$ in $\mathrm{y}=0$ (i.e. $\mathrm{z}=\mathrm{Vt}$ ). As may be seen from Equations (4) and (5), the dy/dz becomes negative small for large $y$, so the dykes walls will slope gently together in the upwards direction. The arctan function never becomes larger than $\pi / 2$, and in that limit we will have a slope:

$$
\mathrm{I}_{\text {Dyke }}=1 / \mathrm{C}_{\mathrm{h}}
$$

This according to the previously estimated $\mathrm{Ch}$ value is of the order 1 meter for each 100 meters in elevation difference. This is not easy to observe in the field, local weaknesses in the host rock make the dyke walls depart from a straight line, and high vertical walls with dykes accessible for measurements are uncommon. Besides, if $\mathrm{S}$ changes to a lower value the width may increase upwards locally.

\subsection{Viscosity and Density}

Viscosity of a flowing basalt intrusion is very difficult to estimate. The magma must be assumed to cool down on its way up. When crystalization begins the flow can stop suddenly if the critical shear stress (yield stress) rises above the shear stress of the flow at the wall. From data in [6] pp. 607-608 the viscosity values in Table $\mathbf{1}$ are derived.

To make an intrusion the dyke has to penetrate the regions of ductile and brittle rock in order to reach the host rock. In these layers the viscosity is very high. The viscosity of the magma that reaches host rock with the properties of Equation (1) in [6] is therefore very difficult to predict. In the following the values $v=0.4 \mathrm{~m}^{2} / \mathrm{s}$, density $\rho_{\mathrm{m}}=2600 \mathrm{~kg} / \mathrm{m}^{3}$ and $\rho_{\mathrm{h}} 100 \mathrm{~kg} / \mathrm{m}^{3}$ higher, will be used as an example.

\subsection{Width Scale and Velocity}

Using Equations (4), (6) and (8), the example values and limiting rules obtained, following values are deducted,

$$
\mathrm{y}_{\max }=9.7 \mathrm{~m} \mathrm{y}_{0}=0.57 \mathrm{~m} \mathrm{~V}=1.0 \mathrm{~m}
$$

As may be seen the magma flows very fast even at this high viscosity, which belongs to the range where the viscosity is very temperature sensitive. This supports the conclusion reach by many earth scientists, that the intrusion process is mainly governed by the magma viscosity which is very temperature dependent.

\section{Variations in the Parameters}

\subsection{Variable Stiffness}

If the stiffness decreases upwards, the flow will at some point go from one formation with value $S_{1}$, to another with value $S_{2}<S_{1}$. As the pressure does not change across the boundary line and the flow $\mathrm{Vy}$ is constant too, we will have:
Table 1. Viscosity of basalt magma.

\begin{tabular}{cccc}
\hline Temperature ${ }^{\circ} \mathrm{C}$ & 1100 & 1150 & 1200 \\
\hline Dynamic viscosity $\mathrm{m}^{2} / \mathrm{s}$ & 42 & 0.4 & 0.1 \\
\hline $\mathrm{y}_{2}=\mathrm{y}_{1} \mathrm{~S}_{1} / \mathrm{S}_{2}, \mathrm{~V}_{2}=\mathrm{V}_{1} \mathrm{~S}_{2} / \mathrm{S}_{1}$
\end{tabular}

The width goes up and the velocity goes down. There will be an elevation range between level 1 and level 2 where the flow adapts to the new environment and in this range Equation (5) does not apply. The length of this range may be estimated of the order of magnitude $\sim y_{\max }$.

\subsection{Variations in Lithostatic Pressure}

An intrusion of a dyke changes the strain rate of the host rock and therefore the lithostatic pressure. This increases the $\mathrm{K}$ value temporarily to almost 1 so new intrusion will have smaller thickness. When the dyke width scale gets too small the intrusion activity can nothing but stop, but field investigations show that intrusions just few centimeter thick do exist. If the example parameters previously estimated are used, he $\mathrm{K}$ value would have to be around 0.99 for so narrow dykes to be formed.

Equation (1) tells us that when a dyke freezes in place, the ratio $\mathrm{K}=\sigma_{3} / \sigma_{1}$ becomes very close to 1 in the vicinity of the new dyke. This will happen in an area of influence that in the first approximation can be viewed as a circle with radius $\mathrm{R}$ of the order of magnitude long, as the length of the dyke, see Figure 2 in [5] and discussion. Further away the pressure disturbance from the emplacement of the dyke will diminish as $1 / \mathrm{R}$ for a big dike, but as $1 / \mathrm{R}^{2}$ for a small one. This is the initial stress-increase disturbance in the host rock; later this disturbance will diminish with time due to transient pressure changes from fluid flow (upper layers) or local plastic deformations.

This is particularly interesting in rift zones like Iceland where the plates are diverging with 1 or 2 centimeters/y. Such a deformation would mean a stress reduction of 0.5 $\mathrm{KPa}$ in a host rock of the previously estimated elasticity $(10 \mathrm{GPa})$ in a $30-40 \mathrm{~km}$ wide rift zone. This is not a large annual pressure change, but would mean a regeneration of a $\mathrm{K}$ increased to a value around 1 , back to about 0.6 in 40 - 50 years. Counting the transient pressure changes too, the regeneration of the $\mathrm{K}$ value could be a lot quicker. No further conclusions can be drawn at the present stage of research, however.

\section{Dykes That Freeze in Place}

When the dyke cools down and the flows stop it must be assumed to happen first at the top. If the top does stop, the flow will not stop immediately but keep going until it has widened the intrusion up to the static $(\mathrm{V}=0$ or the 




Figure 2. Force balance in the magma flow.

equal sign in Equation (1)) value. Calculating the slope of the walls in that situation, we find the exactly same value as Equation (6). This equation is produced by assuming $\operatorname{Arctan}\left(\mathrm{y}_{\max } / \mathrm{y}_{0}\right) \approx \pi / 2$. This means that the form of the dyke is already very close to the static form in most of its height, so very little flow is needed to widen the intrusion. The dyke will, for all practical purposes freeze in place, if just the head is stopped. If the dykes head hits a water on its way up that stops it, the entire dyke stops. The magma flow cannot widen the fissure and get past the plug.

\section{Comparing Dyke Data}

Measuring dyke thicknesses and frequency is standard practice in geological investigations of dyke swarms. If thickness of the same dyke is measured in different elevations the composite stiffness (Ch value) of the host rock can be calculated and the $\mathrm{S}$ estimated. Varying thicknesses will give information on the $\mathrm{K}$ value.

As an example Figure 3 shows a dyke flow from formation 1 to formation 2. In the basalt formations of in east Iceland there is a number of dyke swarms. The geology has been adequately described by Prof. G. P. L. Walker in a series of papers, see [8]. In Table 2 there is an investigation of the Berufjördur complex provided by Magnus Olafsson [13].

It is very uncertain if the increase in dyke thickness from series $\mathrm{B}$ to series $\mathrm{C}$ is significant. There are 96 dykes in the $\mathrm{B}$ series but only 32 in the $\mathrm{C}$ series about 500 meters higher up. Of the 96 there are 69 accessible in the A series and if the change in average thickness from A to B is deemed significant, this would indicate a $15 \%$ decrease in the stiffness $\mathrm{S}$ and the velocity from layer 1 (Figure 1) to layer 2.

\section{Conclusions}

The translator wave theory works very well for the dyke emplacement process. The stress balance between the host rock and the flowing magma is very delicate and very difficult to handle except assuming a piecewise lin-

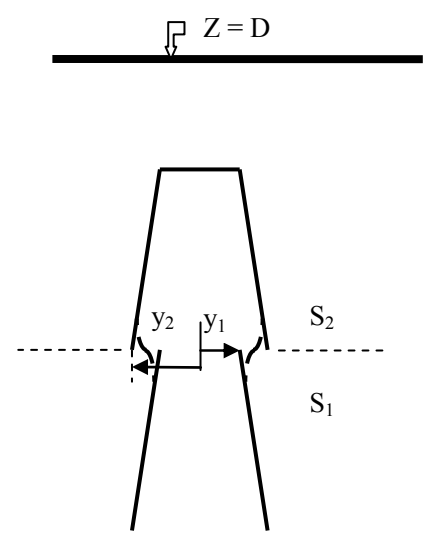

Figure 3. Change of stiffness from $S_{1}>S_{2}$.

Table 2. Average dyke thickness in the Berufjördur complex.

\begin{tabular}{cccc}
\hline & Number & Elevation m.a.s.l. & meters \\
\hline A & 69 & dykes at sea level & 3.4 \\
B & 96 & dykes $100-300$ & 4.0 \\
C & 32 & dykes $>600$ & 4.2 \\
\hline
\end{tabular}

ear relationship between stresses and strain and most researchers do that.

The result of the analysis produces the rather difficult looking Equation (5) for the development of the form of the dyke with time. A closer evaluation shows that the arctangent function can be replaced by its maximum value in most of the dyke's length and has only to be considered in the immediate neighborhood of the head penetrating into the host rock.

Two main parameters control the flow, $\mathrm{y}_{0}$ the width scale and $\mathrm{C}_{\mathrm{h}}$ the composite stiffness of the host rock. They represent the properties of the host rock and the magma, such as elasticity and viscosity.

The theory explains interesting features, known from geological investigations, such as:

1) Dykes have an almost constant thickness, but very variable from dyke to dyke.

2) Viscosity is a very dominating factor.

3) Dykes can widen upwards (teardrop shape).

4) Dykes can freeze in place.

The explanations to these features are following:

1) In a host rock of constant elasticity upwards slope is very small, order of $1 \%$.

2) Higher viscosity increases $y_{0}$ and the stress situation does not allow that.

3) Local width of dyke increases suddenly if the dyke runs into lower elasticity.

4. Width of dyke is very close to the static maximum, the dykes freeze in place if the head stops, e.g. due to cooling.

Following additions that appear to be new are sug- 
gested:

The dyke can penetrate the host rock with constant velocity from bottom to top if the width scale and the composite stiffness of the rock stay constant.

$\mathrm{C}_{\mathrm{h}}$, the composite stiffness of the host rock, is the inclination of the dyke walls. If the inclination can be successfully observed, this important parameter can be observed in the field.

\section{REFERENCES}

[1] J. R. Lister and R. C. Kerr, "Fluid-Mechanical Models of Crack Propagation and Their Application to Magma Transport in Dykes," Journal of Geophysical Research: Solid Earth (1978-2012), Vol. 96, No. B6, 1991, pp. 10049-10077.

[2] J. L. Kavanagh, R. Sparks and J. Stephen, "Insights of Dyke Emplacement Mechanics from Detailed 3D Dyke Thickness," Journal of the Geological Society, Vol. 168, No. 4, 2011, p. 965.

[3] A. Gudmundsson, "Formation of Dykes, Feeder-Dykes, and the Intrusion of Dykes from Magma Chambers," Bulletin Volcanologique, Vol. 47, No. 3, 1984, pp. 537-550. http://dx.doi.org/10.1007/BF01961225

[4] S. R. Spengler and G. P. L. Dike, "Width Characteristics Observed in Intraplate Volcanoes," 2012. http://www.e2hi.com/wp-content/uploads/2012/10/11_Di ke_Width_Paper.pdf

[5] A. M. Rubin, "Propagation of Magma-Filled Cracks," Annual Review of Earth and Planetary Sciences, Vol. 23, 1995, pp. 287-336. http://dx.doi.org/10.1146/annurev.ea.23.050195.001443
[6] H. E. Huppert and R. S. J. Sparks, "The Generation of Granitic Magmas by Intrusion of Basalt into Continental Crust," Journal of Petrology, Vol. 29, No. 3, 1988, pp. 599-624. http://dx.doi.org/10.1093/petrology/29.3.599

[7] D. A. Spence and D. L. Turcotte, "Magma-Driven Propagation of Cracks," Journal of Geophysical Research: Solid Earth (1978-2012), Vol. 90, No. B1, 1985, pp. 575580.

[8] G. P. L. Walker, "The Structure of Eastern Iceland," In: L. Kristjansson, Ed., Geodynamics of Iceland and the North Atlantic Area (NATO ASI volume C11), Reidel Publ. Co., Dordrecht, 1974, pp. 177-188.

[9] J. Elíasson, S. P. Kjaran, S. L. Holm, M. T. Gudmundsson and G. Larsen, "Large Hazardous Floods as Translatory Waves," Environmental Modelling \& Software, Vol. 22, No. 10, 2007, pp. 1392-1399.

[10] J. Elíasson, G. Guigay and B. Karlsson, "Enclosure Fires, Gravity Waves, and the Backdraft Problem," Journal of Fire Sciences, Vol. 26, No. 5, 2008, pp. 373-397. http://dx.doi.org/10.1177/0734904108092116

[11] J. Elíasson, "A Glacial Burst Tsunami near Vestmannaeyjar, Iceland," Journal of Coastal Research, Vol. 24, No. 1, 2008, pp. 13-20. http://dx.doi.org/10.2112/05-0568.1

[12] D. D. Pollard and O. H. Muller, "The Effect of Gradients in Regional Stress and Magma Pressure on the Form of Sheet Intrusions in Cross Section," Journal of Geophysical Research, Vol. 81, No. 5, 1976, pp. 975-984. http://dx.doi.org/10.1029/JB081i005p00975

[13] M. Olafsson, G. A Berufjardarstönd, " $4^{\text {th }}$ Year Science Project,” University of Iceland, 1977. 